\title{
How to Calculate Median Pregnancy-Associated Plasma Protein-A Value to Predict Preeclampsia? Do We Need a Newer Formula?
}

\author{
Burçin KARAMUSTAFAOĞLU BALCI' ${ }^{1}$ İbrahim H. KALELIOĞLU' ${ }^{1}$, Yusuf KILIÇ', Recep HAS ${ }^{1}$, Beyhan ÖMER ${ }^{2}$ \\ Istanbul, Turkey
}

\begin{abstract}
OBJECTIVE: Preeclampsia is one of the major issues in maternal-fetal medicine. Early risk stratification may be beneficial, so is the aim of several researches. Our goal is to investigate whether PAPP-A MoM calculated for first trimester Down syndrome screening or MoM calculated according to Ong's formula can be used to predict the risk of preeclampsia or do we need another method to calculate PAPPA MoM derived from non preeclamptic cases.

STUDY DESIGN: For this retrospective study, data of randomly selected 150 singleton pregnant women who did not develop preeclampsia are used to create a formula to calculate median value of PAPP-A. PAPP-A values of this subgroup are plotted against gestational age and curve fit analysis is done to determine best fitted regression line to get a formula to calculate median value of our cases. PAPP-A MoM values are calculated for each subject according to Ong's formula and our formula. We already had MoM values derived from first trimester screening. ROC curve and Delong's pairwise comparison analyses are used to investigate which MoM value is more predictive for preeclampsia.
\end{abstract}

RESULTS: Although the area under curve value of MoM values derived from this study was the highest, DeLong's pairwise comparison analysis showed no statistically significant difference between the three curves.

CONCLUSION: PAPP-A MoM calculation specific to preeclampsia does not seem to be necessary; PAPP-A MoM obtained from first trimester aneuploidy scan can be used to predict preeclampsia.

Keywords: Pregnancy-associated plasma protein-A, Preeclampsia, Prediction, Down syndrome

Gynecol Obstet Reprod Med 2016;22(3):135-138 DOI: 10.21613/GORM.2016.621

\section{Introduction}

Preeclampsia (PE) affects approximately 5\% of all pregnancies and remains a significant cause of maternal and neonatal morbidity and mortality (1). Early risk stratification may improve the identification of women at highest risk for preeclampsia and provide an opportunity for intervention. The traditional method of screening for PE is maternal history. However, recent studies (2-6) have argued that the new approach in screening for preeclampsia is the incorporation of data coming from maternal characteristics, previous obstetric history and biochemical markers. Thus far, several markers have been evaluated regarding to their ability to predict preeclampsia in the first trimester, prior to onset of clinical signs. One of these markers is Pregnancy Associated Plasma Protein A (PAPP-A). First trimester serum level of PAPP-A is

\footnotetext{
${ }^{\prime}$ Istanbul University Istanbul Faculty of Medicine Department of Obstetrics and Gynecology and 'Department of Biochemistry Fatih, Istanbul

Address of Correspondence: Burcin Karamustafaoğlu Balcl Istanbul Faculty of Medicine Çapa, Fatih, Istanbul, Turkey burcinkaramustafaoglu@yahoo.com

Submitted for Publication: 26.07.2016

Accepted for Publication:
}

lower in preeclamptic women (7-10). Emerging data support that not only preeclampsia but also other pregnancy complications are also associated with low PAPP-A levels $(7,8)$. The median Multiples of Median (MoM) of maternal serum PAPPA was significantly lower in women with small for gestational age $(7,10)$, preterm delivery $(7,10)$, premature delivery $(8)$, and stillbirth (8).

In some researches investigating the relationship between PAPP-A and PE, PAPP-A MoM values are calculated with Ong's formula (11-14). Subjects in Ong's research were pregnancies affected by miscarriage, proteinuric and non proteinuric pregnancy induced hypertension, preterm delivery, growth restriction, and gestational diabetes (7). The aim of this present study is to investigate whether PAPP-a MoM calculated for first trimester Down syndrome screening or MoM calculated according to Ong's formula can be used to predict the risk of preeclampsia, or do we need another method to calculate PAPP-A MoM value derived from non preeclamptic cases only, without excluding cases with other adverse pregnancy outcomes.

\section{Material and Method}

This retrospective study is enrolled in Istanbul Faculty of Medicine, Department of Obstetrics and Gynecology. In our 
department, first trimester screening test is done between $11+$ 0 and $13+6$ weeks of gestation to all women who admit for trisomy screening. Not all women we screen get their prenatal care in our unit, many goes to private hospitals or maternity hospitals or sees a private obstetrician after first trimester screening. All singleton pregnant women initiating prenatal care between January 2010 and September 2011 and getting prenatal care including birth at Istanbul Faculty of Medicine are enrolled in this study. Patients whose pregnancy ended before 20 weeks of pregnancy due to abortion or medical termination because of fetal abnormalities or fetal aneuploidy are excluded. Data during pregnancy and medical records of newborns are collected from all patients and pregnancy related diagnoses are abstracted from these medical records. Informed consent has been obtained from each patient.

In our clinic, first trimester screening is done as it is recommended by Fetal Medicine Foundation. First, the pregnancy is accurately dated according to last menstrual period and crown-rump length. When these two are not consistent, gestational age is calculated according to crown-rump length. The blood is taken on the same day when ultrasound scan is done. Samples are assayed for PAPP-A and free beta hCG using the Kryptor immunoassay analyzer (Brahms, Berlin, Germany; formerly supplied by CIS-Bio International, Burgess Hill, UK).

Blood pressure of pregnant women is measured at every antenatal visit. Hypertensive women are managed in collaboration with the Nephrology Department. All preeclamptic and eclamptic cases and patients with HELLP Syndrome are considered in this study as adverse outcome. No distinction is made between severe and mild preeclampsia neither. Preeclampsia is defined as pregnancy-induced hypertension (systolic blood pressure $\geq 140 \mathrm{~mm} \mathrm{Hg}$; diastolic blood pressure $\geq 90 \mathrm{~mm} \mathrm{Hg}$ ) with proteinuria of at least $300 \mathrm{mg} / 24 \mathrm{~h}$. HELLP Syndrome is defined by hemolysis, elevated liver enzymes with aspartate aminotransferase (AST) greater than $70 \mathrm{U} / \mathrm{L}$ $\left(>2\right.$ SD above mean), and low platelets $\left(<100 \times 10^{(9)} / \mathrm{L}\right)$. All mildly preeclamptic patients and preterm severely preeclamptic patients are managed expectantly. The cases of term severe preeclampsia, eclampsia and HELLP Syndrome are not managed expectantly.

In concern of statistics; age, parity, gravidity, maternal weight at scan, gestational age at birth, birth weight were demographic variables of interest. Maternal age is defined as the age of the mother, in completed years, at term. Maternal weight is measured in kilograms at the time of blood sampling. Data of randomly selected 150 women who did not develop preeclampsia are used to create formula to calculate median value of PAPP-A. PAPP-A measurement values of this subgroup are plotted against gestational age and curve fit analysis is done to determine best fitted regression line to get formula to calculate median value of our cases. PAPP-A MoM values are calculated for each subject first according to our formula, and then according to Ong's Formula, which is "Median PAPP-A value $=10^{\wedge}((0.179 * \mathrm{GA})-1.74)$ ". We already had MoM values derived from first trimester screening. ROC curve is used to investigate which MoM value is more predictive for preeclampsia. For this reason, each ROC curve is compared with another one with Delong's pairwise comparison analysis.

\section{Results}

A total of 1349 singleton pregnant women initiating prenatal care between January 2010 and September 2011 and getting prenatal care including birth at Istanbul Faculty of Medicine are enrolled in this study. 32 patients whose pregnancy ended before 20 weeks of pregnancy due to abortion or medical termination because of fetal abnormalities or fetal aneuploidy are excluded. 1270 patients did not develop preeclampsia whereas $47(3.57 \%)$ developed (adverse outcome). The mean age is $29.46 \pm 5.36$. The median gravida is 2 (min:1, max:14). The median parity is 1 (min: 0, max:7). The mean maternal weight at first trimester is $62.67 \pm 11.13$ kilograms. The mean gestational age at birth is $37.5 \pm 4.3$. The mean birth weight is $3092.84 \pm 814$ grams.

We determined that more appropriate regression lines were quadratic and cubic, both had $\mathrm{r}$ square value of 0,113 , using data of randomly selected 150 subjects. Quadratic regression line is chosen to calculate our median values due to the simplicity of its formula. Our formula, derived from quadratic regression line of data of 150 subjects, is "Median PAPP-A value $=-23.001-\left(4.364^{*} \mathrm{GA}\right)+\left(0.23^{*}\left(\mathrm{GA}^{\wedge} 2\right)\right)^{\prime}$ ". Ong's formula to calculate median value is "Median PAPP-A value $=10^{\wedge}$ $((0.179 * \mathrm{GA})-1.74)$ ". For each case, two MoM values derived from these two formulas and MoM value derived from first trimester screening are used for ROC curve analyses (Figure 1).

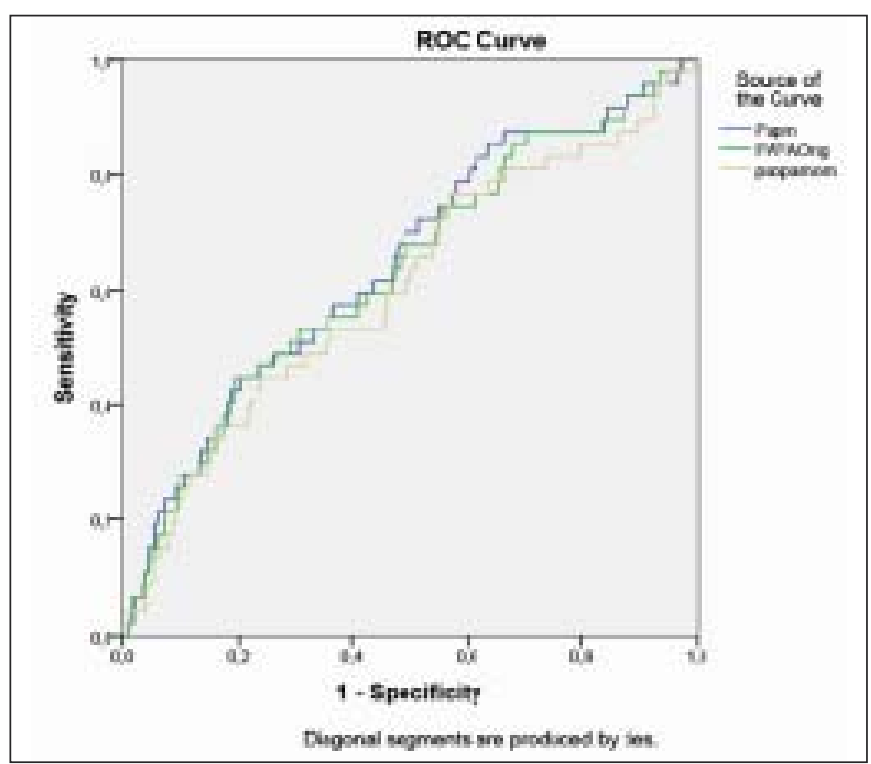

Figure 1: ROC curves

Predictivity of different cut-off levels of these MoM values, obtained from coordination of ROC curves, are represented in table 1 . 
Table 1: Sensitivity of all three pregnancy associated plasma protein a values in predicting preeclampsia

\begin{tabular}{|l|l|l|l|l|}
\hline & & $\begin{array}{l}\text { \%5 False } \\
\text { Positive }\end{array}$ & $\begin{array}{l}\text { \%15 False } \\
\text { Positive }\end{array}$ & $\begin{array}{l}\text { \%20 False } \\
\text { Positive }\end{array}$ \\
\hline \multirow{2}{*}{ PAPP-A (this study) } & Cut-off & $\leq 0.34$ & $\leq 0.47$ & $\leq \mathbf{0 . 5 2}$ \\
\cline { 2 - 5 } & Sensitivity & $\% 19.1$ & $\% 34$ & $\% 44.7$ \\
\hline PAPP-A (Ong) & Cut-off & $\leq 0.5$ & $\leq 0.69$ & $\leq 0.77$ \\
\cline { 2 - 5 } & Sensitivity & $\% 14.9$ & $\% 31.9$ & $\mathbf{\% 4 4 . 7}$ \\
\hline PAPP-A (11-14 gw) & Cut-off & $\leq 0.4$ & $\leq 0.56$ & $\mathbf{0 . 6 1}$ \\
\cline { 2 - 5 } & Sensitivity & $\% 12.8$ & $\% 31.9$ & $\% .2$ \\
\hline
\end{tabular}

Ong: According to ong's formula, gw: Gestational week, 11-14gw: According to first trimester trisomy screening formula

Area under curve values were $0.646,0.635$ and 0.605 , respectively for MoM values derived from this study, Ong's study and first trimester screening (Table 2). Although the area under curve value of MoM values derived from this study was the highest, DeLong's pairwise comparison analysis showed no statistically significant difference between the three curves.

Table 2: Area under curves calculated for each formula

\begin{tabular}{ll}
\hline & AUC \\
\hline PAPP-A MoM (this study) & 0.646 \\
PAPP-A MoM (Ong) & 0.635 \\
PAPP-A MoM (11-14 gw) & 0.605 \\
\hline
\end{tabular}

AUC: Area under curve, Ong: According to Ong's formula, 1114, gw: According to first trimester trisomy screening formula

\section{Discussion}

While PAPP-A MoM calculated for first trimester aneuploidy screening is currently used to predict preeclampsia, we investigated whether a newer formula to calculate PAPP-A MoM specific to preeclampsia can be used to make PAPP-A MoM a stronger indicator of preeclampsia. This study showed that our formula did not differ from the other two formulas in predicting preeclampsia.

PAPP-A is a syncytiotrophoblast-derived metalloproteinase, which enhances the mitogenic function of the insulinlike growth factors by cleaving the complex formed between such growth factors and their binding proteins $(15,16)$. The insulin-like growth factor system is believed to play an important role in placental growth and development, it is therefore not surprising that low serum PAPP-A is associated with a higher incidence of PE. In 2000, Ong et al. demonstrated that maternal serum PAPP-A at 10-14 weeks of gestation is lower in pregnancies resulting in miscarriage, pregnancy induced hypertension, growth restriction and in those with pre-existing diabetes mellitus or those who develop gestational diabetes (7). This research is a keystone for researches about PAPP-A and unfavorable pregnancy outcomes. It is now well known that in chromosomally normal pregnancies low maternal serum PAPP-A is associated with increased risk for subsequent development of preeclampsia (7-10).
Preeclampsia is a very common pregnancy complication associated with serious maternal-fetal morbidity and mortality $(2,17-20)$. The ability to predict in very early pregnancy those women at risk for preeclampsia might decrease maternal and fetal morbidity through closer surveillance by physicians specialized in high-risk obstetrics, as well as delivery at tertiary care centers. At present, no blood test or ultrasound marker or anything else exist to predict preeclampsia with high sensitivity and high specificity. A low first-trimester PAPP-A MoM is an indicator of preeclampsia but not a strong indicator. Measurement of PAPP-A is not an effective method of screening for preeclampsia because only $8-23 \%$ of affected cases have serum levels below the $5^{\text {th }}$ centile, which is about 0.4 MoM (21). When our formula is used; PAPP-A MoM value lower than 0.52 predicts PE with a sensitivity of $44.7 \%$ and false positivity of $20 \%$. As low PAPP-A MoM values do not directly orient to invasive procedures or as false positivity do not emerge tests or interventions which have risks for patients, high false positivity is acceptable in using PAPP-A for predicting PE.

Unfortunately, the predictivity of low PAPP-A MoM for $\mathrm{PE}$ is definitely not high. That's the reason why scientists are trying to find how to improve the detection rate of women at risk for preeclampsia. New approach in prenatal care is to combine maternal characteristics and medical history with the results of a series of biophysical and biochemical markers to find the women at high risk for preeclampsia (2-6). Such an approach needs a complicated algorithm, some calculations which includes PAPP-A MoM value. When formulas to calculate MoM value for PAPP-A are complex, the algorithm is getting harder. Our research showed that PAPP-A MoM value calculated by our formula was not statistically different than the other formulas in predicting PE, so calculating PAPP-A MoM by a newer formula is not needed, PAPP-A MoM that we get from first trimester screening can be used for the prediction of PE.

The obstetrician should be aware of the increased risk for PE when managing patients having a chromosomally normal fetus and low PAPP-A level during first-trimester screening for trisomies. It has been previously demonstrated that women 
with a low first-trimester PAPP-A MoM and a fetus with normal karyotype should be followed up further; this approach would allow intensive maternal and fetal monitoring, leading to earlier diagnosis of $\mathrm{PE}$ with the potential for mitigating an adverse outcome. PAPP-A MoM value obtained from aneuploidy scan can be a marker for further investigations for preeclampsia, such as using complex prediction formulas or referring the patient for Doppler investigation at first or second trimester.

\section{Conclusion}

Our research shows that more complicated PAPP-A MoM calculations specific to preeclampsia do not seem to be necessary; the PAPP-A MoM derived from first trimester aneuploidy scan can be used to predict PE.

\section{References}

1. Karumanchi SA, Maynard SE, Stillman IE, et al. Preeclampsia: a renal perspective. Kidney Int 2005; 67(6):2101-2113

2. Poon LC, Stratieva V, Piras S, Piri S, Nicolaides KH. Hypertensive disorders in pregnancy: combined screening by uterine artery Doppler, blood pressure and serum PAPP-A at 11-13 weeks. Prenat Diagn 2010;30(3):216-23.

3. Poon LC, Kametas NA, Chelemen T, Leal A, Nicolaides KH. Maternal risk factors for hypertensive disorders in pregnancy: a multivariate approach. J Hum Hypertens 2010;24(2):104-10.

4. Poon LC, Kametas NA, Maiz N, Akolekar R, Nicolaides KH. First-trimester prediction of hypertensive disorders in pregnancy. Hypertension 2009; 53(5):812-8.

5. Akolekar R, Syngelaki A, Poon L, Wright D, Nicolaides $\mathrm{KH}$. Competing risks model in early screening for preeclampsia by biophysical and biochemical markers. Fetal Diagn Ther 2013; 33(1):8-15.

6. Poon LC, Akolekar R, Lachmann R, Beta J, Nicolaides $\mathrm{KH}$. Hypertensive disorders in pregnancy: screening by biophysical and biochemical markers at 11-13 weeks. Ultrasound Obstet Gynecol 2010;35(6):662-70.

7. Ong CY, Liao AW, Spencer K, Munim S, Nicolaides KH. First trimester maternal serum free beta human chorionic gonadotrophin and pregnancy associated plasma protein A as predictors of pregnancy complications. BJOG 2000; 107(10):1265-70.

8. Smith GC, Stenhouse EJ, Crossley JA, Aitken DA, Cameron AD, Connor JM. Early pregnancy levels of pregnancy-associated plasma protein a and the risk of intrauterine growth restriction, premature birth, preeclampsia, and stillbirth. J Clin Endocrinol Metab 2002;87(4): 1762-7.
9. Spencer K, Cowans NJ, Nicolaides KH. Low levels of maternal serum PAPP-A in the first trimester and the risk of pre-eclampsia. Prenat Diagn 2008;28(1):7-10.

10. Ranta JK, Raatikainen K, Romppanen J, Pulkki K, Heinonen S. Decreased PAPP-A is associated with preeclampsia, premature delivery and small for gestational age infants but not with placental abruption. Eur J Obstet Gynecol Reprod Biol 2011;157(1):48-52.

11. Spencer K, Cowans NJ, Nicolaides KH. Low levels of maternal serum PAPP-A in the first trimester and the risk of pre-eclampsia. Prenat Diagn 2008;28(1):7-10.

12. Spencer K, Cowans NJ, Avgidou K, Molina F, Nicolaides $\mathrm{KH}$. First-trimester biochemical markers of aneuploidy and the prediction of small-for-gestational age fetuses. Ultrasound Obstet Gynecol 2008;31(1):15-9.

13. Spencer K, Cowans NJ, Molina F, Kagan KO, Nicolaides KH. First-trimester ultrasound and biochemical markers of aneuploidy and the prediction of preterm or early preterm delivery. Ultrasound Obstet Gynecol 2008;31 (2):147-52.

14. Spencer K, Cowans NJ, Avgidou K, Nicolaides KH. Firsttrimester ultrasound and biochemical markers of aneuploidy and the prediction of impending fetal death. Ultrasound Obstet Gynecol 2006;28(5):637-43.

15. Bonno M, Oxvig C, Kephart GM, Wagner JM, Kristensen T, Sottrup-Jensen L,et al. Localization of pregnancy-associated plasma protein-A and colocalization of pregnancyassociated plasma protein-A messenger ribonucleic acid and eosinophil granule major basic protein messenger ribonucleic acid in placenta. Lab Invest 1994;71(4):560-6.

16. Lawrence JB, Oxvig C, Overgaard MT, Sottrup-Jensen L, Gleich GJ, Hays LG, et al. The insulin-like growth factor (IGF)-dependent IGF binding protein-4 protease secreted by human fibroblasts is pregnancy-associated plasma protein-A. Proc Natl Acad Sci USA 1999;96(6):3149-53.

17. World Health Organization: Make Every Mother and Child Count. World Health Report, 2005. Geneva, World Health Organization 2005;45-64.

18. Confidential Enquiry into Maternal and Child Health (CEMACH) Perinatal Mortality 2006: England, Wales and Northern Ireland. London, CEMACH 2008. Chapter 5. p. 71 .

19. Duley L. The global impact of pre-eclampsia and eclampsia. Semin Perinatol 2009;33(3):130-7.

20. Centre for Maternal and Child Enquiries (CMACE). Perinatal Mortality 2008: UK London CMACE 2010. chapter 5. p.41.

21. Poon LC, Maiz N, Valencia C, Plasencia W, Nicolaides KH. First-trimester maternal serum pregnancy-associated plasma protein-A and pre-eclampsia. Ultrasound Obstet Gynecol 2009;33(1):23-33. 